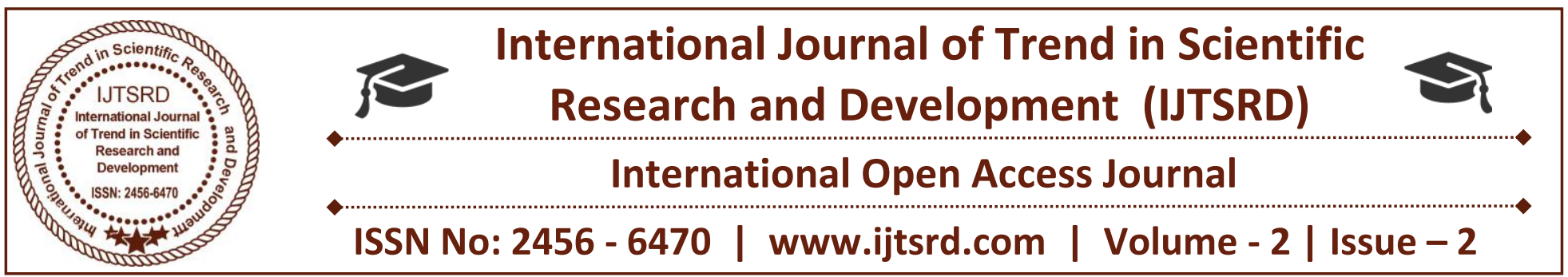

\title{
A Review on Rural Marketing in India: Oppurtunities, Challenges and Strategies
}

\author{
Pooja Yadav \\ Assistant Professor, Indira Gandhi University, \\ Meerpur, Rewari, Haryana, India
}

\section{ABSTRACT}

India's growth move is highly driven by the development of the rural people. Rural marketing is a developing concept, and the marketers have realized the opportunity of growth in the market recently. Due to green revolution, the rural areas are consuming a large quantity of industrial and manufactured products. In this way rural market offers opportunities in the form of large untapped market, increase in disposable income, increase in literacy level and large scope for penetration. To take the advantage of these opportunities, a special marketing strategy 'Rural Marketing' has emerged. Rural markets offer a great scope for a concentrated marketing effort because of the recent increase in the rural incomes. Such incomes will increase faster because of better production and higher prices for agricultural commodities. A large number of businesses are involved in the marketing of various products in the rural areas of India and elsewhere. Though there is huge potential and substantial growth opportunities in the rural markets, yet there are some challenges too, which caused hurdles in tapping rural markets. The paper describes the opportunities, challenges and strategies of rural marketing in India. This study is a step forward in exploring various strategies to be adopted in the rural market along with the current scenario of rural marketing, highlighting key challenges related to rural marketing.

Keywords: Rural marketing, Challenges in rural marketing, Rural marketing strategies, Rural Consumers

\section{INTRODUCTION}

The rural market has been growing steadily over the past few years and is now even bigger than the urban market. About 70 per cent of India's population lives in villages. More than 800 million people live in villages of India. 'Go rural' is the marketer's new slogan. Indian marketers as well as multinationals, such as Colgate-Palmolive, Godrej and Hindustan Lever have focused on rural markets. Broadly rural marketing incorporates the marketing of agricultural products, rural industries products and services of many kinds. The trade channels for different types of commodities available in rural areas are private, cooperatives, processors, regulated markets and state agencies. In no sense, a social cluster or village economy as at whole can, be developed without effective and efficient rural marketing. Very little attention has been paid in the planning era towards the development of rural marketing. In fact marketing is a dynamic state of affairs and is part and parcel of the whole economy. Thus production and marketing are the two facets of a coin. Rural marketing constitutes the nerve centre of rural development activities.

Rural marketing is now a two-way marketing process. There is inflow of products into rural markets for production or consumption and there is also outflow of products to urban areas. The urban to rural flow consists of agricultural inputs, fast-moving consumer goods (FMCG) such as soaps, detergents, cosmetics, textiles, and so on. The rural to urban flow consists of agricultural produce such as rice, wheat, sugar, and 
cotton. There is also a movement of rural products within rural areas for consumption.

Since the $1980^{\text {ee }} \mathrm{s}$ the mass rural market was used to attract the marketers in Indian consumer market. The fact that $70 \%$ of country ${ }^{\text {ee }} \mathrm{s}$ population was unaddressed, which was the major attraction for marketers. In recent time this attraction has increased with the additional money that comes into hands of rural consumers due to green revolution, rise in Agriproduce prices and MNREGA spending. Budget 2013 further strengthens the rural story with MNREGA because there has been a substantial increase in their spending. These initiatives shift the rural consumers towards Brands. Rural market constitute an important segment of overall economy, for example in USA, 55 million people reside in rural areas (Kotni, 2012). Government agencies like IRDA (Insurance Regulatory and Development Authority) and NCAER (National Council for Applied Economics Research) define rural as a village with a population less than 5000 with $75 \%$ male population engaged in agriculture, while Hindustan lever, ITC and most FMCG companies define rural as any place with a population below 20,000.

\section{REVIEW OF LITERATURE}

According to NCAER, a rural Market is any market that exists in the rural area with a population less than 10,000 , where the real density of population at any population nucleation is low without any significant infrastructure. (NCAER.). According to Census of India 2001, out of total population of 102.7 crores, 74.2 crore are in rural areas (Census of India 2001). That makes it 72.2 percent of the country's population. Also, in absolute terms, the rural population is increasing at a higher rate than urban population. The significance of these figures is that even a small percentage increase in overall income would lead to addition of a large number of customers bringing in much needed volumes (Ramakrishnan 2006).

(Sharma and Katewa (2005) discussed in his study that the rural market in India is made up of two broad compartments. One, which deals in consumer products produced by industries and the second which deals in farm produce.

Srinivas (2007) stated that the India Retail Industry is the largest among all the industries, accounting for over 10 per cent of the country's GDP and around 8 per cent of the employment. The Retail Industry in India has come forth as one of the most dynamic and fast paced industries with several players entering the market. But all of them have not yet tasted success because of the heavy initial investments that are required to break even with other companies and compete with them. The India Retail Industry is gradually inching its way towards becoming the next boom industry.

\section{OBJECTIVES OF THE STUDY}

- To understand the concept of Rural Marketing.

- To identify the opportunities in the area of Rural marketing.

- To discuss the challenges and strategies of Rural marketing.

\section{METHODOLOGY OF THE STUDY}

The study is a descriptive method. The Secondary data were collected from different sources, such as, text books, magazines, articles and websites.

\section{OPPORTUNITIES IN INDIAN RURAL MARKETING}

* More than 750 million people * Estimated annual size of the rural market

\begin{tabular}{|l|l|}
\hline FMCG & Rs. 70,000 Crore \\
\hline Durables & Rs. 5,500 Crore \\
\hline Agricultural-Inputs (including tractors) & Rs. 48,000 Crore \\
\hline 2 / 4 Wheelers & Rs. 8,400 Crore \\
\hline
\end{tabular}

\section{Increase in Literacy Rate}

Literacy rate is increasing in rural areas. According to census 2011 it stood at $68.9 \%$ (2001 census $58.7 \%)$.There are more graduates in rural than in urban India. This brings social and cultural changes in buying behavior of the rural customers and more aware about national and international brand. Due to 
International Journal of Trend in Scientific Research and Development (IJTSRD) ISSN: 2456-6470

increase in literacy rate they get jobs in nearby towns. owned homes in the villages, they have high They earn urban salaries but continue to live in self purchasing power and prefer to buy branded product.

\begin{tabular}{|l|l|l|l|}
\hline & \multicolumn{3}{|l|}{ Table: Increase in literacy rate } \\
\hline & 2001 & 2011 & Difference \\
\hline Overall India & 64.8 & 74 & 9.2 \\
\hline Rural & 58.7 & 68.9 & 10.2 \\
\hline Urban & 79.9 & 85 & 5.1 \\
\hline
\end{tabular}

Increasing in disposable income and purchasing power

Projects from private companies and the rural employment initiatives by the Government like MNREGA (Mahatma Gandhi National Rural Employment Guarantee Act) schemes have given the rural population an opportunity to meet their daily needs. Government decided to expand the agriculture loan at lower rate of interest and distribute million of Kisan Credit Cards, has given a boost to the income level to the rural sector. According to advanced estimates of national income released by center statistic organization "The Per Capita income at current prices during 2011-12 is estimated to be Rs. 60,972 compared to Rs. 53,332 during 2010-11 showing a rise of $14.3 \%$. Companies have the opportunity to enter in this new market and take the advantage of increased disposable income.

\section{Reduction of Risk during Recession}

It has been observed that companies which cater both urban and rural markets tackle the recession in the better way. The demands for goods in the urban market often follow a cyclic whereas in the rural market it is steady. So companies can safeguard themselves from the harmful effects of recession after entering in the rural market.

\section{IT Penetration in Rural India}

Today's rural children and youth will grow up in an environment where they have, information access ${ }^{\text {ee }}$ to education opportunities, job opportunities, government schemes, world wide news and mandi prices. Rural areas offer a great potential for growth in internet usage with the number of claimed internet users in these spaces to be reached at 45 million by Dec. 2012, according to the recent IMRB survey, conducted jointly with internet and Mobile Association of India (IMAI). The number of claimed internet users has witnessed a compounded annual growth rate of $73 \%$ since Dec. 2010. As the electronic ethos and IT culture moves into rural India, the possibility of change are becoming visible.

\section{Infrastructure improving rapidly}

In 50 years only, $40 \%$ villages have been connected by roads, in next 10 years another $30 \%$ would be connected. Rural telephone density has gone up by $300 \%$ in the last 10 years. Government of India is planning its most ambitious national program in Jan.2013 to facilitate electricity through decentralized renewable energy sources. The government aims to provide LED lights to around 400million homes that do not have an electricity connection by 2017. Rapid development of rural infrastructure is also major attraction for marketers.

\section{CHALLENGES}

The peculiarities of rural markets and rural consumers pose challenges to marketers in reaching them effectively. There are a large number of small villages which are not easily accessible because of all weather roads. The main challenges of rural marketing are discussed below:

Transportation: Transportation is an important aspect in the process of movement of products from urban production centers to remote villages. The transportation infrastructure is extremely poor in rural India. Due to this reason, most of the villages are not accessible to the marketing man.

Communication: Marketing communication in rural markets suffers from a variety of constraints. The literacy rate among the rural consumers is very low. Print media, therefore, have limited scope in the rural context. 
Availability of appropriate media: It has been estimated that all organized media in the country put together can reach only 30 per cent of the rural population of India. The print media covers only 18 per cent of the rural population. The radio network, in theory, covers 90 per cent. But, actual listenership is much less. TV is popular, and is an ideal medium for communicating with the rural masses. But, it is not available in all interior parts of the country.

Warehousing: A storage function is necessary because production and consumption cycles rarely match. Many agricultural commodities are produced seasonally, whereas demand for them is continuous. The storage function overcomes discrepancies in desired quantities and timing. In warehousing too, there are special problems in the rural context.

Village structure in India: In our country, the village structure itself causes many problems. Most of the villages are small and scattered. It is estimated that 60 per cent of the villages are in the population group of below 1,000. The scattered nature of the villages increases distribution costs, and their small size affects economic viability of establishing distribution points.

Rural markets and sales management: Rural marketing involves a greater amount of personal selling effort compared to urban marketing. The rural salesman must also be able to guide the rural customers in the choice of the products. It has been observed that rural salesmen do not properly motivate rural consumers. The rural salesman has to be a patient listener as his customers are extremely traditional.

Inadequate banking and credit facilities: In rural markets, distribution is also handicapped due to lack of adequate banking and credit facilities. The rural outlets require banking support to enable remittances, to get replenishment of stocks, to facilitate credit transactions in general, and to obtain credit support from the bank.

Market segmentation in rural markets: Market segmentation is the process of dividing the total market into a number of sub-markets. The heterogeneous market is broken up into a number of relatively homogeneous units.
Branding: The brand is the surest means of conveying quality to rural consumers. Day by day, though national brands are getting popular, local brands are also playing a significant role in rural areas. This may be due to illiteracy, ignorance and low purchasing power of rural consumers.

Packaging: As far as packaging is concerned, as a general rule, smaller packages are more popular in the rural areas. At present, all essential products are not available in villages in smaller packaging. The lower income group consumers are not able to purchase large and medium size packaged goods

\section{STRATEGIES FOR RURAL MARKETING}

The past practices of treating rural markets as appendages of the urban market is not correct, since rural markets have their own independent existence, and if cultivated well could turn into a generator of profit for the marketers. But the rural markets can be exploited by realizing them, rather than treating them as convenient extensions of the urban market.

\section{a) Marketing Strategy}

Marketers need to understand the psychology of the rural consumers and then act consequently. Rural marketing involves more exhaustive personal selling efforts compared to urban marketing. Firms should abstain from designing goods for the urban markets and subsequently pushing them in the rural areas. To effectively tap the rural market, a brand must associate it with the same things the rural folks do. This can be done by utilizing the various rural folk media to reach them in their own language and in large numbers so that the brand can be associated with the myriad rituals, celebrations, festivals, "melas", and other activities where they assemble.

\section{b) Distribution Strategy}

One of the ways could be using company delivery van which can serve two purposes - it can take the products to the customers in every nook and corner of the market, and it also enables the firm to establish direct contact with them, and thereby facilitate sales promotion. Annual "melas" organized are quite popular and provide a very good platform for distribution because people visit them to make several purchases. According to the Indian Market Research Bureau, around 8000 such melas are held in rural India every year. Rural markets have the practice of fixing specific days in a week as Market Days called "Haats' when exchange of goods and services are 
carried out. This is another potential low cost distribution channel available to the marketers. Also, every region consisting of several villages is generally served by one satellite town termed as "Mandis" where people prefer to go to buy their durable commodities. If marketing managers use these feeder towns, they will easily be able to cover a large section of the rural population.

\section{c) Promotional Strategy}

Marketers must be very careful while choosing the mediums to be used for communication. Only $16 \%$ of the rural population has access to a vernacular newspaper. So, the audio visuals must be planned to convey a right message to the rural folk. The rich, traditional media forms like folk dances, puppet shows, etc., with which the rural consumers are familiar and comfortable, can be used for high impact product campaigns. Radio is also very popular source of information and Entertainment, Adds on radio can also be a helpful tool for marketers.

\section{CONCLUSION}

Rural marketing is a developing concept, and as a part of any economy has untapped potential; marketers have realized the opportunity recently. Improvement in infrastructure and reach promise a bright future for those intending to go rural. Any macro-level strategy for these markets should focus on availability, accessibility and affordability. In spite of having so many challenges in rural marketing the companies have shown considerable interest in the rural India and have tried to market themselves using the 4A model which says that the products marketed should be acceptable by the rural population, the products should be easily available, they should be affordable and most importantly an awareness drive should be created to educate people about the products. In concluding remark, if the company wants to capture the rural market, they must first carry on the detailed and earnest analysis of the countryside goal market, aiming at the particular characteristics of the rural market, and utilizing different marketing strategy according to concrete situations.

\section{REFERENCES}

1. NCAER. New Perspectives in Marketing. New Delhi: NCAER.

2. Ramakrishnan, R. (2006). Rural Marketing: Importance and issues. In R. Ramakrishnan, Rural Marketing in India - Strategies and Challenges ( $\mathrm{p}$. 205). New Delhi: New Century Publications.

3. Sharma,Y. K., \& Katewa, R. (2005). Challenges of Rural Marketing. In A. Saxena, Samiuddin, H. Dwivedi, \& M. Rahman, Rural Marketing (p. 420). Jaipur: National Publishing House.

4. Srinivas Kastoori \& Jagtap Jyothi (2007) Indian Retailing Perspectives: Its Growth, Challenges and Opportunities, The Indian Commerce Association working paper $\mathrm{Pp}-26$

\section{Digital Websites:}

1. http://blogs.worldbank.org

2. http://www.icytales.com

3. http://iasscore.in

4. http://en.wikipedia.org

5. Www.google.com 